will be linked to articles and posted on the Web site within days of submission.

The Journal also publishes "letters to the editor" that comment on published articles, or other topics of interest to the readership. Such correspondence is indexed in MEDLINE. Letters for publication consideration should be submitted via the author portal on the Journal home page.

Victoria Neale, $\mathrm{PbD}, \mathrm{MPH}$

JABFM

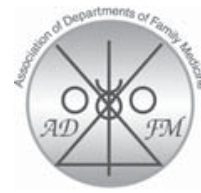

From the Association of Departments of Family Medicine

Ann Fam Med 2006;4:89. DOI: 10.1370/afm.505.

\section{THE FAMILY MEDICINE ROAD TO THE NIH ROADMAP}

The genesis of modern family medicine did not include a strong consideration of research. After World War II, considerable resources were allocated to medical care. This was a period when medical technology flourished and specialization grew. There was growth of academic health centers with a focus on research. By 1966 the social construct of medicine had changed to the point where people were asking the question, "Who is going to take care of us?" In 1966 this resulted in the formation of 3 commissions: the Millis Commission, the Willard Committee, and the Folsom Commission. The result was a call for the creation of a new medical specialty, one spawned by a perceived need for more primary care. Research in family medicine was not recognized as a priority at this point. By 1970 we had new, residency-trained family physicians. Departments of Family Medicine were forming in medical schools around the country. At that time the essential component of having a department was having a residency. The leaders of these departments were often physicians who had been in practice and were politically astute enough to navigate their way into and through medical school politics, often with the support and assistance of the state chapters of the American Academy of Family Physicians (AAFP). Then came the growth of predoctoral programs and required clerkships in family medicine. During this time of proliferation, a strong interest in pedagogical methodology developed. It was not until the last decade of the 20th century that research began to gain importance, but by this time there was a paucity of the necessary infrastructure, especially the lack of mentors and the leadership to create a culture for research.

Today family medicine is still trying to play catchup. But the goal is not necessarily to catch up with our partners at the academic health center. Rather, the research agenda is to create a primary care system that will meet the needs of the US population. The NIH Roadmap articulates the need to get scientific results closer to those who will need them, the patients. This "translation" as it is called today, is not a new concept; 10 years ago AHRQ (then known as the Agency for Health Care Policy and Research) had "dissemination" as a major priority after earlier work had shown that it takes far too long for the results of cutting-edge research to become general practice.

There are 3 main themes in the Roadmap. ${ }^{1-3}$ The first, called New Pathways to Discovery, involves primarily a basic science agenda. The other 2 themes, Research Teams of the Future and Reengineering the Clinical Research Enterprise, offer opportunities for family medicine researchers. Included are clinical research training programs, an understanding of the value of interdisciplinary research, and a recognition of the need to have somebody on the ground who actually sees patients for a living (the end note of translation). This is where practice-based research networks become necessary to the National Institutes of Health (NIH) mission as laboratories for understanding the results of innovation.

It is imperative that family medicine continue to advocate for research in the $\mathrm{NIH}$. We have had some degree of success with more investigators receiving funding and increased funding of larger grants, including grants from specific Roadmap initiatives. This funding would not have been possible without a growth in the number of researchers, most of whom are faculty in academic units trained to do competitive research. Our discipline must continue to create a nurturing research culture to enhance the potential for those who represent our research vanguard. ${ }^{4} \mathrm{~A}$ part of this culture is the promotion of collaboration with other disciplines. We could benefit from increasing the number of family medicine representatives who serve on $\mathrm{NIH}$ study sections. We must also increase our influence on how requests for applications (RFAs) are worded to make sure that NIH understands how primary care contributes to true translation and the overall research of the nation. The barriers to family medicine on the road to the Roadmap can be overcome.

Mark S. Jobnson, MD, MPH and the Association of Departments of Family Medicine

\section{References}

1. Zerhouni E. Medicine. The NIH Roadmap. Science. 2003;302:63-72.

2. Zerhouni EA. Translational and clinical science--time for a new vision. N Engl J Med. 2005;353:1621-1623.

3. National Institutes of Health. NIH roadmap for medical research. Available at: http://nihroadmap.nih.gov.

4. Bland C, Weber-Main A, Lund SM, Finstad DA. The Research-Productive Department: Strategies From Departments That Excel. Bolton, MA: Anker Publishing Co. Inc; 2005. 